Check for updates

Cite this: RSC Adv., 2019, 9, 560

Received 20th November 2018 Accepted 14th December 2018

DOI: $10.1039 / c 8 r a 09562 k$

rsc.li/rsc-advances

\section{Adsorption and anion exchange insight of indigo carmine onto CuAl-LDH/SWCNTs nanocomposite: kinetic, thermodynamic and isotherm analysis $\uparrow$}

\author{
Noha Almoisheer, ${ }^{a}$ F. A. Alseroury, ${ }^{a}$ Rajeev Kumar, (D) ${ }^{b}$ M. Aslam (iD c \\ and M. A. Barakat iD *bd
}

Two-dimensional layered materials are gaining much attention in the field of wastewater purification. Herein, we report the synthesis and characterization of an anion selective copper-aluminum-layered double hydroxide/single-walled carbon nanotubes (CuAl-LDH/SWCNTs) composite for the scavenging of organic dye indigo carmine (IC) from aqueous solution. A facile urea hydrolysis method was used for the controlled growth of the metal hydroxides over the SWCNTs. Structural characterization of the prepared materials was investigated using X-ray photoelectron spectroscopy (XPS), scanning electron microscopy (SEM), and X-ray diffraction (XRD) techniques. The obtained results revealed that the CUAI-LDH/SWCNTS composite has a higher potential for the removal of IC in comparison to CuAlLDH and SWCNTs. The enhanced adsorption capacity of the composite revealed that deposition of CUAl-LDH over SWCNTs increases the active adsorption sites and promotes the interactions between the composite and IC dye via anion exchange, electrostatic, $\pi-\pi$, hydrogen bonding etc. Moreover, adsorption kinetics, isotherms, and thermodynamic studies have been also proposed to illustrate the mechanism of the IC adsorption onto the CUAL-LDH/SWCNTs composite. Thermodynamic parameters showed that the adsorption of IC dye onto the CUAL-LDH/SWCNTS composite was exothermic and spontaneous in nature. Intra-particle diffusion was determined to be the rate-limiting step and adsorption of IC followed the Langmuir isotherm model with the maximum monolayer adsorption capacity $294.117 \mathrm{mg} \mathrm{g}^{-1}$ at $20{ }^{\circ} \mathrm{C}$. The results suggest that the CuAl-LDH/SWCNTs composite is a potential material for IC adsorption in aqueous solution.

\section{Introduction}

The application of various types of dyes and pigments in a variety of industries such as the textile, cosmetics, plastics, paper, printing etc. industries, releases a large amount of colored substances into wastewater streams..$^{\mathbf{1 - 4}}$ Wastewater effluents containing dyes cause major problems in the environment due to their color and their breakdown products. ${ }^{5}$ The toxic nature of dyes may cause allergies, skin irritation and even are carcinogenic. ${ }^{6,7}$ Indigo carmine (IC) is an anionic dye and used in various industries such as the textile, food, and cosmetics industries. IC is a highly toxic dye which

\footnotetext{
${ }^{a}$ Department of Physics, Faculty of Science, King Abdulaziz University, Kingdom of Saudi Arabia

${ }^{b}$ Department of Environmental Sciences, Faculty of Meteorology, Environment and Arid Land Agriculture, King Abdulaziz University, Jeddah, 21589, Kingdom of Saudi Arabia. E-mail: mabarakat@gmail.com; Fax: +96626952364; Tel: +96626400000 ext. 64821 ${ }^{c}$ Center of Excellence in Environmental Studies, King Abdulaziz University, Kingdom of Saudi Arabia

${ }^{d}$ Central Metallurgical R \& D Institute, Helwan 11421, Cairo, Egypt

$\dagger$ Electronic supplementary information (ESI) available. See DOI: 10.1039/c8ra09562k
}

causes irritation to the eye, respiratory tract and skin. ${ }^{7,8}$ Due to their toxicity, it is necessary to remove dyes from contaminated water before discharging to the environment. There are different techniques used to treat wastewater, such as coagulation/flocculation, ozone treatment, chemical oxidation, membrane filtration, ion exchange, photocatalytic degradation, and adsorption..$^{3,4,9}$ The adsorption processes have proven to be one of the best treatment methods because of their high efficiency, low price, easy operation and handling. ${ }^{\mathbf{1 , 4 6 , 9 , 1 0}}$ Different types of natural and synthetic adsorbents have been used to treat wastewaters containing dyes including CNTs, ${ }^{1,5}$ agricultural waste, ${ }^{2,4}$ graphene oxide, ${ }^{6}$ activated carbons, ${ }^{11}$ zeolite,${ }^{12}$ clay, ${ }^{13}$ polymers ${ }^{7,14}$ and their composites. However, disadvantages of these adsorbents are low adsorption capacities and separation inconvenience. Hence, there is a need to investigate new promising adsorbents having high adsorption capacity in a short time. ${ }^{\mathbf{1 4}}$ Recently, the growth of nanotechnology has improved water treatment technology by representing the suggestion that many water quality issues could be resolved or greatly ameliorated using nanotechnology products. ${ }^{\mathbf{1 , 6 , 1 5}}$ 
Since the discovery, carbon nanotubes (CNTs) attracts the attention of researchers around the world due to their excellent properties and applications in a variety of fields. ${ }^{\mathbf{1 , 5 , 1 6 , 1 7}}$ The application of the CNTs in the field of wastewater purification as an adsorbent has been explored and a large number of the articles have been published which are revealing its potential as an excellent adsorbent due to a large specific surface area and tubular structure. ${ }^{\mathbf{1 , 1 6 , 1 7}}$ However, expensive cost, separation from the aqueous solution and their hydrophobic surface may limit the CNTs application as an adsorbent., ${ }^{1,5,16,17}$ In recent year, the disadvantages related to CNTs can be conquering through making composites with polymers, chitosan, activated carbon fabric, graphene, metal oxides etc. ${ }^{1,18-22}$

In last decade, two-dimensional nanomaterials such as graphene oxide, graphitic carbon nitride, boron nitride, metal-layered double hydroxide etc. are gaining the much attention due to higher stability, large surface area, high adsorption capacity and reusability. ${ }^{22}$ Metal-layered double hydroxide has attracted huge attention due to its applications such as anion exchanger, catalysis, photochemistry, electrochemistry, environmental applications and so forth. ${ }^{23,25}$ Metal-layered double hydroxide including hydrotalcite and hydrotalcite-like are a versatile class of ionic clay. ${ }^{24-26}$ Metallayered double hydroxide has the general formula $\mathbf{M}_{a}{ }^{2+} \mathbf{M}_{b}^{3+}(\mathrm{OH})_{+2 a+2 b}{ }^{-}\left(\mathrm{X}^{-}\right) \cdot x \mathrm{H}_{2} \mathrm{O}$, where two kinds of metal ion, $\mathrm{M}^{2+}$ is a divalent metal cation and $\mathrm{M}^{3+}$ as trivalent metal cation, forming the layered structure together with hydroxyl groups, an interlayer anion, and water molecules. The interlayer anions can be exchanged between layers where the $\mathrm{H}_{2} \mathrm{O}$ molecules are placed. ${ }^{25-28}$ Recently, the use of the metallayered double hydroxide as an adsorbent has been investigated by several researchers. Ahmad et al., ${ }^{8}$ synthesized the $\mathrm{Mg} / \mathrm{Fe}-\mathrm{LDH}$ for the removal of IC dye. The adsorption of phosphate by biochar composite with $\mathrm{Mg}-\mathrm{Al}$ and $\mathrm{Mg}-\mathrm{Fe}-\mathrm{LDH}$ was investigated by Wan et al. ${ }^{29}$ The authors reported that LDH based biochar composite showed the fast and efficient removal of the phosphate ions. Sepehr et al., ${ }^{30}$ used the $\mathrm{Mg} /$ Al-LDH for the removal of metronidazole antibiotic form the aqueous solution and the maximum adsorption capacity was $62.804 \mathrm{mg} \mathrm{g}^{-1}$. Previous studies showed that LDH are the good adsorbents for the removal of wastewater contaminants. ${ }^{8,29-31}$ Due to the presence of exchangeable anions and 2D layered structure, metal-layered double hydroxide based materials are the good adsorbent for the removal of anionic pollutants. ${ }^{\mathbf{8} 29,30}$ Given the various attractive and anion selective features of the metal-layered double hydroxide, we hypothesized that if we decorate them onto the SWCNTs, then we can combine the feature of both materials into the single phase to enhance the IC scavenging properties.

Herein, synthesis of CuAl-LDH/SWCNTs nanocomposite for the scavenging of anionic IC molecules has been investigated. The prepared CuAl-LDH/SWCNTs nanocomposite showed highly selective behaviors with high adsorption capacity for IC molecules. Moreover, different kinetics and isotherm models are also fitted to the experimental data to investigate the adsorption mechanism.

\section{Materials and method}

\subsection{Materials}

Indigo carmine dye, molecular formula $\mathrm{C}_{16} \mathrm{H}_{8} \mathrm{~N}_{2} \mathrm{Na}_{2} \mathrm{O}_{8} \mathrm{~S}_{2}$, color index $=73015$, molecular mass as $466.36 \mathrm{~g} \mathrm{~mol}^{-1}$ and maximum light adsorption $\lambda_{\max }=610 \mathrm{~nm}$ was purchased from Merck. Single-walled carbon nanotubes (SWCNTs) synthesized using CVD method were purchased from Beijing Deke Daojin Science and Technology Co., Ltd, China, with an average $1.1 \mathrm{~nm}$ diameter, surface area $450 \mathrm{~m}^{2} \mathrm{~g}^{-1}$ and the purity were above $95 \%$. The length of these tubes was in the range of 5-30 $\mu \mathrm{m}$.

\subsection{Synthesis of CuAl-LDH/SWCNTs composite}

For the synthesis of CuAl-LDH/SWCNTs nanocomposite, a hydrothermal method was used. Initially, $1.23 \mathrm{~g}$ SWCNT was suspended in $50 \mathrm{ml}$ of deionized water and then solubilized by sonication for $1 \mathrm{~h}$. The used salts for copper and aluminum were $\mathrm{Cu}(\mathrm{II})$ or $\mathrm{Al}(\mathrm{III})$ salts used were $\mathrm{CuSO}_{4}$ and $\mathrm{Al}\left(\mathrm{NO}_{3}\right)_{3}$. Thereafter, $25 \mathrm{ml}$ of each, $0.05 \mathrm{M} \mathrm{Cu}$ (II) and $0.0166 \mathrm{M} \mathrm{Al}$ (III) were added into the SWCNTs solution. After vigorous stirring for $30 \mathrm{~min}, 25 \mathrm{ml}$ of $0.25 \mathrm{M}$ urea was added and continuously stirred for $1 \mathrm{~h}$. The resulting mixture was transferred to a Teflon lined hydrothermal autoclave reactor. The reactor was heated at $140{ }^{\circ} \mathrm{C}$ for $18 \mathrm{~h}$ and left the reactor until cool down to room temperature. The obtained product was filtered, thoroughly washed with de-ionized water, acetone and then dried at $105{ }^{\circ} \mathrm{C}$ for $24 \mathrm{~h}$. The pure CuAl-LDH material was also synthesized using the same method without adding SWCNTs.

\subsection{Characterizations}

The surface morphology of pure SWCNTs and CuAl-LDH/ SWCNTs nanocomposite was studied by (FE-SEM) (JSM 7600F; JEOL - Japan). XRD patterns of pure SWCNTs and CuAlLDH/SWCNTs nanocomposite were analyzed by X-ray diffractometer (Ultima-IV; Rigaku, Japan) operating at $40 \mathrm{kV}$ and 40 $\mathrm{mA}$ over the range $(2 \theta)$ of $10-80$. The $\mathrm{Cu} \mathrm{K} \alpha$ X-ray source with a wavelength of $0.154056 \mathrm{~nm}$ was used. The X-ray photoelectron spectroscopy (XPS) spectra of CuAl-LDH/SWCNTs was recorded with a (SPECS GmbH, Germany) spectrometer using a nonmonochromatic $\mathrm{Mg}-\mathrm{K} \alpha(1253.6 \mathrm{eV}) \mathrm{X}$-ray source $(100 \mathrm{~W})$ with $13.5 \mathrm{kV}$ at $10^{-10}$ mbar base pressure.

\subsection{Adsorption analysis}

The adsorption properties of the synthesized materials were investigated in a batch process using $20 \mathrm{ml}$ IC solution of fix concentrations and at constant temperatures. A fixed amount of adsorbent $(10 \mathrm{mg})$ was used and the $\mathrm{pH}$ of the IC solutions was varied from 2 to 10 . The desired $\mathrm{pH}$ of the solution was adjusted using $0.1 \mathrm{M} \mathrm{HCl}$ and $0.1 \mathrm{M} \mathrm{NaOH}$ solutions. The adsorption equilibrium time studies were performed at the reaction time ranges from 0 to $360 \mathrm{~min}$ at fix $\mathrm{pH}$ and concentration. The isotherm and thermodynamics studies were performed at the temperature varied between 20 to $40{ }^{\circ} \mathrm{C}$ and IC solution concentrations range from 50 to $500 \mathrm{mg} \mathrm{L}^{-1}$. UV-visible spectrophotometer (UV-1800, Shimadzu, Japan) was used for 
determination of initial and residual IC concentration in the solutions. The adsorption capacity of the prepared adsorbents was determined by the following equation

$$
q_{\mathrm{e}}=\frac{\left(C_{0}-C_{\mathrm{e}}\right) V}{m}
$$

where $C_{0}$ and $C_{\mathrm{e}}$ are the initial and remaining IC dye concentration in solution $\left(\mathrm{mg} \mathrm{L}^{-1}\right)$, respectively in time $t . q_{\mathrm{e}}$ represent adsorption capacity $\left(\mathrm{mg} \mathrm{g}^{-1}\right)$. $V$ and $m$ are the sample volume in (L) and adsorbent mass in (g).

\section{Results and discussion}

\subsection{Synthesis and characterization of CuAl-LDH/SWCNTs nanocomposite}

The synthesis of the CuAl-LDH/SWCNTs nanocomposite is performed by the urea hydrolysis method under the hydrothermal conditions as shown in Fig. 1. The urea releases the carbonate and hydroxides upon heating which form the monodisperse hydrotalcite particles in the presence of $\mathrm{Cu}^{2+}$ and $\mathrm{Al}^{3+}$ with a good crystallinity degree and form the metal hydroxides. ${ }^{32}$

The crystallinity and structure of both SWCNTs and CuAlLDH/SWCNTs composite were recorded by XRD as depicted in Fig. 2. The diffraction pattern of pure SWCNTs showing the peaks at $2 \theta^{\circ}-25.8$ and 42.55 which correspond to diffraction of the (002) and (100) of graphitic planes of the SWCNTs. The XRD pattern of CuAl-LDH/SWCNTs showed the characteristic peaks for the graphitic carbon at the almost same position and also showed the sharp peaks revealing the crystallinity and reflections for the deposited CuAl-LDH structure. These reflections are the characteristics of LDH in like hydrotalcite phase. ${ }^{27}$

The SEM images of SWCNTs and CuAl-LDH/SWCNTs composite are shown in Fig. S1. $\dagger$ A significant change in the morphology of SWCNTs (Fig. S1a image after the decoration of CuAl-LDH (Fig. S1b $\dagger$ ). The pure SWCNTs are showing the bundle like structure (Fig. S1a†ं) while

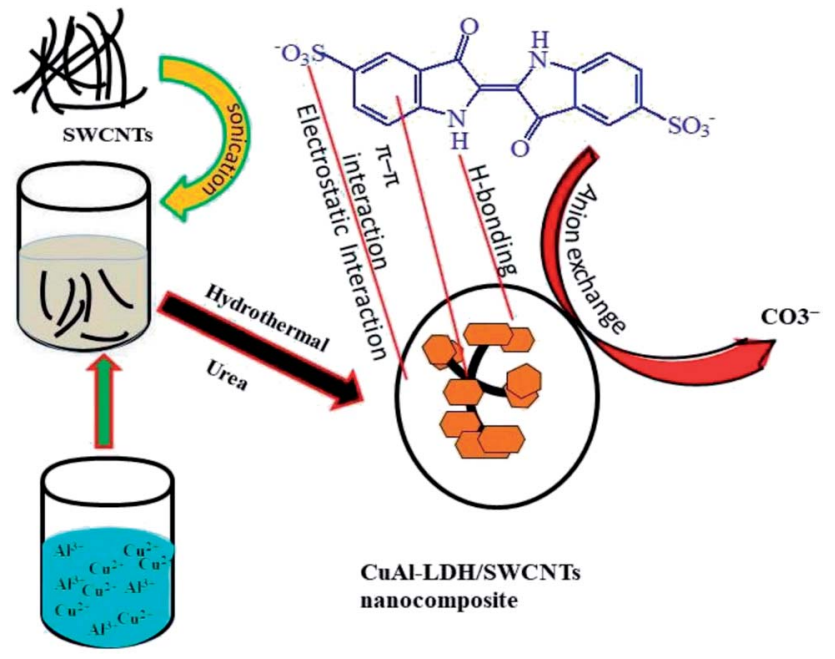

Fig. 1 A schematic diagram for the synthesis of CuAl-LDH/SWCNTs nanocomposite.

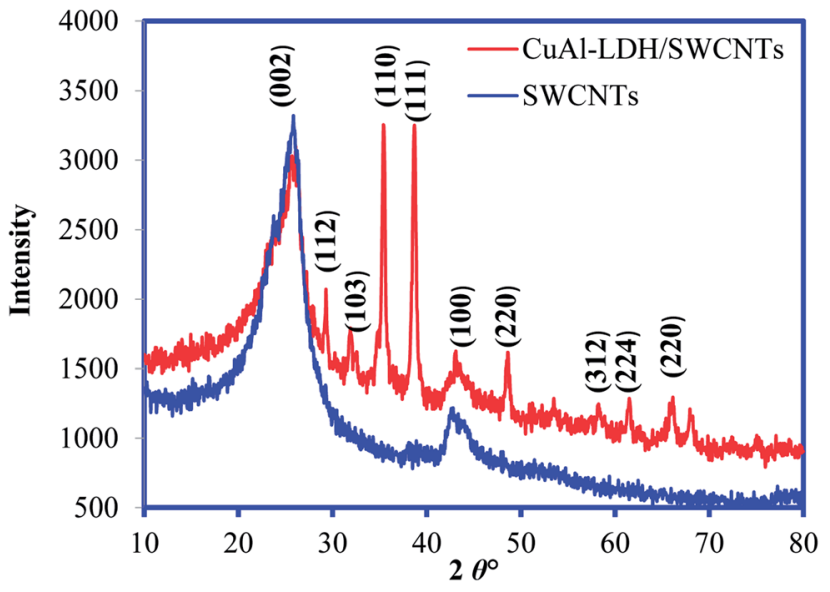

Fig. 2 XRD pattern of SWCNTs and CuAl-LDH/SWCNTs nanocomposite.

SEM image (Fig. S1b $\dagger$ ) of CuAl-LDH/SWCNTs composite showing the successful deposition of the CuAl-LDH onto SWCNTs. Moreover, to confirm the presence of the CuAl-LDH in the composite, XPS analysis is performed.

The XPS analysis of CuAl-LDH/SWCNTs composite was performed to determine the elemental composition and oxidation state of the individual elements in the composite. Fig. 3a showing the XPS survey spectrum demonstrates the elemental composition of CuAl-LDH/SWCNTs which revealing the \% atomic concentration of C 1s (86.168\%), O 1s (12.172\%), Cu 2p $(1.112 \%)$ and $\mathrm{Al} 2 \mathrm{p}(0.548 \%)$ at the binding energy of 284.45 , $532.75,933.15$ and $76.15 \mathrm{eV}$, respectively. The deconvoluted high resolution spectra (Fig. $3 \mathrm{~b}$ ) of $\mathrm{Cu} 2 \mathrm{p}$ shows the peaks at 933.05 $\mathrm{eV}$ (individual $\mathrm{Cu}^{2+}$ centers), $934.15 \mathrm{eV}$ (clustered $\mathrm{Cu}^{2+}$ species) corresponding to $\mathrm{Cu} 2 \mathrm{p}_{3 / 2}$ and while the peak at 952.75 eV belongs to $\mathrm{Cu} 2 \mathrm{p}_{1 / 2} \cdot{ }^{27}$ The main $\mathrm{C} 1 \mathrm{~s}$ peak in Fig. $3 \mathrm{c}$ located at $284.45 \mathrm{eV}$ is assigned to $\mathrm{sp}^{2}$ carbon from SWCNTs. Also, there were relatively weak peaks located at $285.9 \mathrm{eV}$, $287.3 \mathrm{eV}$ and $289.35 \mathrm{eV}$ corresponding to the $\mathrm{C}-\mathrm{O}$ bond, $\mathrm{C}=\mathrm{O}$ bond, and $\mathrm{O}-\mathrm{C}=\mathrm{O}$ bond, respectively. ${ }^{33}$ The XPS spectrum of $\mathrm{O}$ 1s (Fig. 3d) shows a strong peak corresponding to the $\mathrm{O}-\mathrm{H}$ bond of the carboxyl group on the SWCNT surface. ${ }^{34}$ Fig. 3e shows a high-resolution spectrum of $\mathrm{Al} 2 \mathrm{p}$ appears at the binding energy $75.6 \mathrm{eV}$ which indicate the presence of $\mathrm{Al}^{3+}$ in $\mathrm{Al}-\mathrm{OH} .^{35}$

\subsection{Indigo carmine adsorption studies}

3.2.1. Effect of solution $\mathbf{p H}$ and adsorption mechanism. The solution $\mathrm{pH}$ is considered one of the main factors which control the interaction between the adsorbent and adsorbate. The uptake of the IC molecules by the CuAl-LDH, SWCNTs and CuAl-LDH/SWCNTs nanocomposite at the different solution $\mathrm{pH}$ is shown in Fig. 4. The results show that adsorption capacity order: CuAl-LDH < SWCNTs < CuAl-LDH/SWCNTs for IC at all the studied $\mathrm{pH}$. The results revealed that the acidic solution conditions are favorable for the removal of IC molecules and optimum adsorption is observed at $\mathrm{pH} 2 .^{36}$ The adsorption capacity of CuAl-LDH/SWCNTs nanocomposite for IC is $196.78 \mathrm{mg} \mathrm{g}^{-1}$ which is evidently greater than that of both 

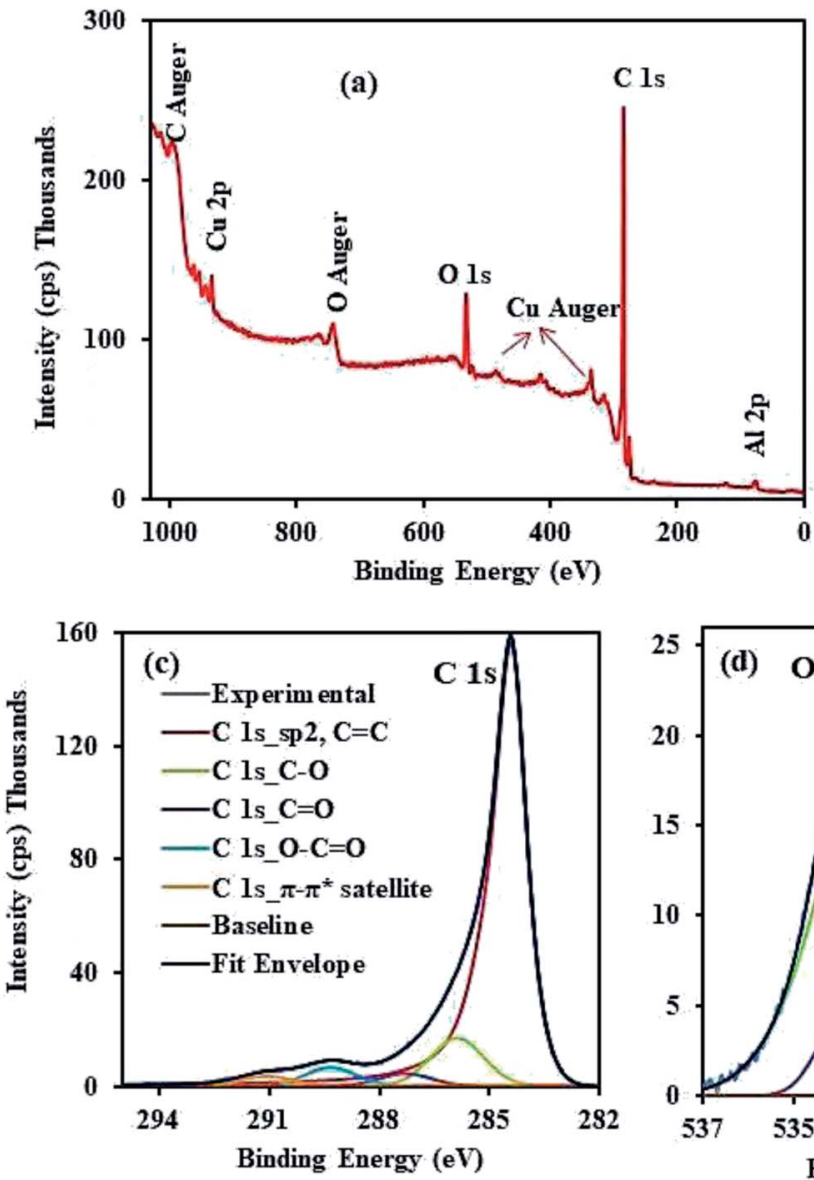
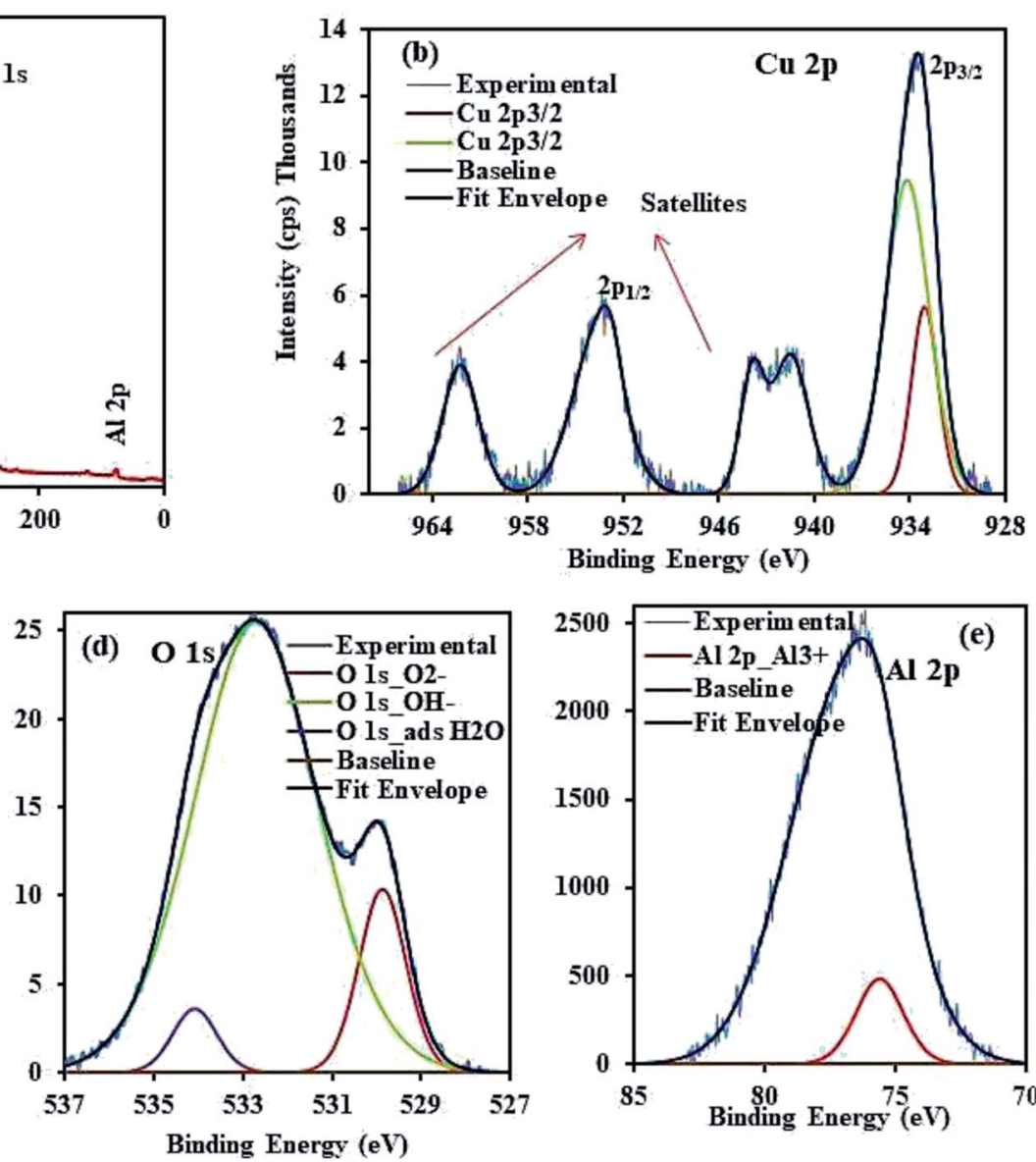

Fig. 3 XPS analysis of CuAl-LDH/SWCNTs nanocomposite (a) survey, and high resolution spectra of (b) Cu $2 p$ (c) C 1s (d) O 1s and (e) Al $2 p$.

SWCNTs $\left(179.5 \mathrm{mg} \mathrm{g}^{-1}\right)$ and CuAl-LDH $\left(89.46 \mathrm{mg} \mathrm{g}^{-1}\right)$. The higher adsorption of the IC onto the CuAl-LDH/SWCNTs nanocomposite can be explained on the basis of the hybrid nature of the composite which has the properties of the CuAl-

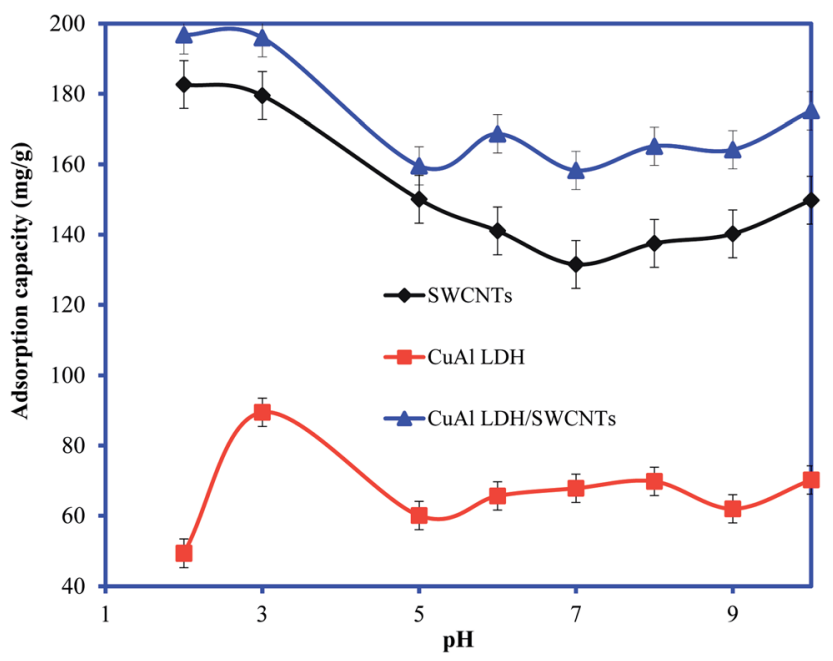

Fig. 4 Plot for the adsorption of IC molecules onto CuAl-LDH, SWCNTS and CUAL-LDH/SWCNTs nanocomposite at varying solution $\mathrm{pH}$. (Conc. $100 \mathrm{mg} \mathrm{L}^{-1}, \mathrm{~V} 20 \mathrm{ml}$, temp. $20^{\circ} \mathrm{C}$, time $6 \mathrm{~h}, \mathrm{~m} \mathrm{0.01)}$ ).
LDH and SWCNTs and having a large number of the functional groups compared to the CuAl-LDH and SWCNTs. The adsorption of IC onto all studies adsorbents, CuAl-LDH, SWCNTs and CuAl-LDH/SWCNTs decreases with the increase in the solution $\mathrm{pH}$. The changes in the IC uptake behavior at varying solution $\mathrm{pH}$ can be explained on the basis of ionexchangeable groups, $\mathrm{H}^{+}$and $\mathrm{OH}^{-}$in the solution under acidic and basic medium. The possible reaction mechanism between the adsorbent and anionic IC molecules $\left({ }^{-}\right.$IC) are representing as follows:

$(\mathrm{CuAl}-\mathrm{LDH} / \mathrm{SWCNTs})^{+} \mathrm{X}^{-}+{ }^{-} \mathrm{IC} \rightarrow(\mathrm{CuAl}-\mathrm{LDH} /$ SWCNTs) ${ }^{+} \cdot{ }^{-} \mathrm{IC}+\mathrm{X}^{-}$(anion exchange)

$(\mathrm{CuAl}-\mathrm{LDH} / \mathrm{SWCNTs})^{+} \mathrm{X}^{-}+\mathrm{H}^{+} \rightarrow{ }^{+} \mathrm{H} \cdot(\mathrm{CuAl}-\mathrm{LDH} /$ SWCNTs) ${ }^{+} \cdot \mathrm{X}^{-}$(under acidic conditions)

\section{${ }^{+} \mathrm{H}(\mathrm{CuAl}-\mathrm{LDH} / \mathrm{SWCNTs})^{+} \mathrm{X}^{-}+2 \mathrm{IC}^{-} \rightarrow \mathrm{IC}^{-} \cdot{ }^{+} \mathrm{H}(\mathrm{CuAl}-\mathrm{LDH} /$ SWCNTs) ${ }^{+} \cdot{ }^{-}$IC (anion exchange and electrostatic interaction in acidic conditions)}

where, $\mathrm{X}^{-}$represents the anionic species in CuAl-LDH layers and ${ }^{-}$IC is anionic IC molecules. Moreover, under basic conditions, $\mathrm{OH}^{-}$are in excess in the solution which generates the negative charge on the surface of the adsorbent resulted in 


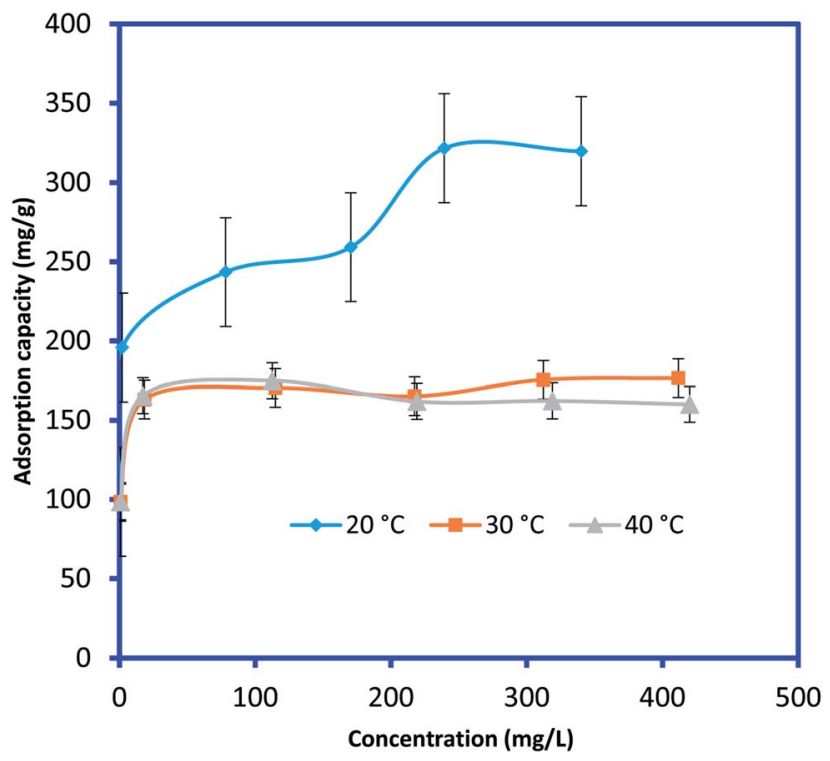

Fig. 5 Effect of initial IC dye concentration and solution temperature on IC adsorption onto CuAl-LDH/SWCNTs nanocomposite $(V 20 \mathrm{ml}$, time $6 \mathrm{~h}, m 0.01 \mathrm{~g}, \mathrm{pH}$ 2).

electrostatic repulsion forces develop between the anionic IC molecules and negatively charged CuAl-LDH/SWCNTs nanocomposite. The anion exchange also reduced due to the presence of excessive $\mathrm{OH}^{-}$and there is a completion between $\mathrm{OH}^{-}$ ions and ${ }^{-}$IC molecules for the same site. Thus, adsorption of

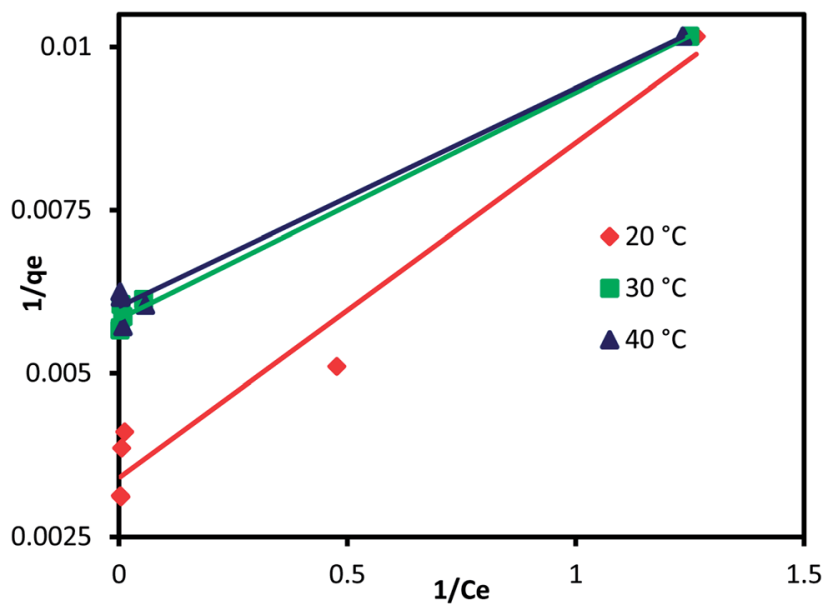

Fig. 6 Langmuir isothermal plot for adsorption of IC onto CuAl-LDH/ SWCNTs nanocomposite. the IC reduced in the basic $\mathrm{pH}$ conditions. ${ }^{37}$ Besides the electrostatic forces and anion exchange mechanism, some other forces such as van der Waals forces, $\pi-\pi$ interaction, $\mathrm{H}$ bonding, and physical adsorption are also responsible for the adsorption of the IC molecules onto the CuAl-LDH/SWCNTs nanocomposite as shown in Fig. 1. The SWCNTs sidewalls are hydrophobic in nature due to higher $\pi$ election density of $\mathrm{sp}^{2}$ carbon atom which may interact with the IC molecules via hydrophobic interactions. Moreover, the $\pi$ system of the SWCNTs in nanocomposite may interact with $\pi$ bond $(\mathrm{C}=\mathrm{C})$ in the benzene ring of the IC molecules and establish the $\pi-\pi$ interaction. The carboxylic and hydrophilic groups present on the CuAl-LDH/SWCNTs nanocomposite also form the H-bond with the nitrogen and oxygen-based functional groups presents in IC molecular structure. ${ }^{\mathbf{1 , 7 1 1}}$ A schematic mechanism for the adsorption of IC molecules onto the CuAl-LDH/SWCNTs nanocomposite is shown in Fig. 1.

3.2.2. Adsorption isotherms and thermodynamics. In order to determine the effect of IC concentration and temperature, the adsorption studies were performed at the concentration ranges from 50 to $500 \mathrm{mg} \mathrm{L}^{-1}$ and temperature at 20, 30, and $40{ }^{\circ} \mathrm{C}$, respectively. The results are depicted in Fig. 5 and an increase in temperature has a negative impact on IC adsorption while the adsorption of the IC molecules rises with the increase in the initial IC concentration in the solution. The adsorption capacity of IC onto CuAl-LDH/SWCNTs nanocomposite decreased from 259.16 to $161.86 \mathrm{mg} \mathrm{g}^{-1}$ with a rise in solution temperature from 20 to $40{ }^{\circ} \mathrm{C}$. The decrease in the uptake of IC may refer to the deformation of the adsorption sites on CuAlLDH/SWCNTs nanocomposite and exothermic nature of adsorption process. ${ }^{36}$ Moreover, to find the effect of IC concentration and solution temperature on the interaction between the IC molecules and CuAl-LDH/SWCNTs nanocomposite, Langmuir $^{38}$ and Freundlich ${ }^{39}$ isotherm models are applied to the adsorption data. The linear equation for the Langmuir and Freundlich isotherm models are as follows;

$$
\begin{aligned}
\frac{1}{q_{\mathrm{e}}} & =\frac{1}{C_{\mathrm{e}} K_{\mathrm{L}} q_{\mathrm{m}}}+\frac{1}{q_{\mathrm{m}}} \\
\ln q_{\mathrm{e}} & =\frac{1}{n} \ln C_{\mathrm{e}}+\ln K_{\mathrm{F}}
\end{aligned}
$$

where $q_{\mathrm{m}}\left(\mathrm{mg} \mathrm{g}^{-1}\right)$ is the CuAl-LDH/SWCNTs nanocomposite maximum monolayer adsorption capacity of IC molecules and $K_{\mathrm{L}}\left(\mathrm{L} \mathrm{mg}^{-1}\right)$ is the free energy of adsorption. Both $q_{\mathrm{m}}\left(\mathrm{mg} \mathrm{g}^{-1}\right)$ and $K_{\mathrm{L}}\left(\mathrm{L} \mathrm{mg}^{-1}\right)$ are the Langmuir constant. $C_{\mathrm{e}}\left(\mathrm{mg} \mathrm{L}^{-1}\right)$ is the IC equilibrium concentration. The Freundlich constant, $K_{\mathrm{F}}$ denote

\begin{tabular}{|c|c|c|c|c|c|c|}
\hline Temp. ${ }^{\circ} \mathrm{C}$ & \multicolumn{3}{|c|}{ Langmuir isotherm model } & \multicolumn{3}{|c|}{ Freundlich isotherm model } \\
\hline 30 & 172.413 & 1.657 & 0.9930 & 107.018 & 11.148 & 0.8500 \\
\hline 40 & 166.66 & 1.818 & 0.9839 & 111.396 & 13.404 & 0.7000 \\
\hline
\end{tabular}

Table 1 Isotherm parameters for the removal of IC onto CuAl-LDH/SWCNTs nanocomposite 
Table 2 Thermodynamic parameters for IC adsorption onto CuAlLDH/SWCNTs nanocomposite

\begin{tabular}{llll}
\hline Temperature $\left({ }^{\circ} \mathrm{C}\right)$ & $\Delta G^{\circ} \mathrm{kJ} \mathrm{mol}^{-1}$ & $\Delta H^{\circ} \mathrm{kJ} \mathrm{mol}^{-1}$ & $\Delta S^{\circ} \mathrm{J} \mathrm{mol}^{-1} \mathrm{~K}^{-1}$ \\
\hline 20 & -30.822 & & \\
30 & -34.170 & 38.784 & 0.2383 \\
40 & -35.539 & &
\end{tabular}

the adsorption capacity and $n$ represents adsorption intensity. Fig. 6 and S2 $\uparrow$ shows the plots for Langmuir and Freundlich isotherms model applied for the IC removal by CuAl-LDH/ SWCNTs nanocomposite, respectively. The parameters values calculated from their respective plots are tabulated in Table 1 and the obtained values for the parameters revealing that the adsorption of IC onto CuAl-LDH/SWCNTs nanocomposite followed the Langmuir isotherm model which suggesting the monolayer adsorption of IC molecules onto the CuAl-LDH/ SWCNTs nanocomposite surface. ${ }^{8}$ The obtained $q_{\mathrm{m}}$ values at 20, 30 and $40{ }^{\circ} \mathrm{C}$, are 294.117, 172.413 and $166.66 \mathrm{mg} \mathrm{g}^{-1}$, respectively, which are close to the experimental data. The adsorption capacity of the CuAl-LDH/SWCNTs nanocomposite for IC is higher than the previously reported adsorbents such as raw Brazil nut shells - $1.09 \mathrm{mg} \mathrm{g}^{-1}$, $^{40}$ palm wood cellulose activated carbon - $1.85 \mathrm{mg} \mathrm{g}^{-1},{ }^{41}$ bio- $\mathrm{MnO}_{x} \mathrm{C}-45.95 \mathrm{~g} / 0.1 \mathrm{~g},{ }^{42}$ $\mathrm{Fe} / \mathrm{Mg}-\mathrm{LDH}-55 \mathrm{mg} \mathrm{g}^{-1},{ }^{8}$ chitin -5.75 and chitosan $-71.82 \mathrm{mg}$ $\mathrm{g}^{-1}$. $^{-}$

The thermodynamic parameters values for the adsorption of IC onto CuAl-LDH/SWCNTs nanocomposite are calculated using the following equations.

$$
\begin{aligned}
& \ln K_{\mathrm{L}}=\frac{\Delta S^{\circ}}{R}-\frac{\Delta H^{\circ}}{R T} \\
& \Delta G^{\circ}=-R T \ln K_{\mathrm{L}}
\end{aligned}
$$

where, $\Delta G^{\circ}, \Delta H^{\circ}$, and $\Delta S^{\circ}$ are the free energy change (kJ mol ${ }^{-1}$ ), enthalpy change $\left(\mathrm{kJ} \mathrm{mol}^{-1}\right)$, and entropy change $\left(\mathrm{J} \mathrm{mol}^{-1} \mathrm{~K}^{-1}\right)$, respectively. $K_{\mathrm{L}}$ is the Langmuir constant $\left(\mathrm{L} \mathrm{mol}^{-1}\right)$. A plot of Van't Hoff, $\ln K_{\mathrm{L}}$ versus $1 / T$, is shown in Fig. $\mathrm{S} 3 \dagger$ and the obtained values for the thermodynamic parameters are tabulated in Table 2. As the negative $\Delta G^{\circ}$, IC adsorption onto CuAl$\mathrm{LDH} / \mathrm{SWCNTs}$ nanocomposite is spontaneous in nature. ${ }^{42}$ The value of $\Delta H^{\circ}$ is positive, indicating the exothermic adsorption of IC and onto CuAl-LDH/SWCNTs nanocomposite. A positive value of $\Delta S^{\circ}$ demonstrates an increasing randomness at the onto CuAl-LDH/SWCNTs nanocomposite IC solution interface during the adsorption process. ${ }^{43,44}$

3.2.3. IC adsorption kinetics. The adsorption of IC molecules onto CuAl-LDH/SWCNTs nanocomposite at the varying contact time is shown in Fig. 7a. The uptake of IC gradually rises as the times increases and shows a fast adsorption at the initial $100 \mathrm{~min}$. Thereafter, adsorption of IC onto CuAl-LDH/SWCNTs nanocomposite become slow because of complete anion exchange and saturation of all the active sites within $230 \mathrm{~min}$. The initial fast removal of the IC was mainly due to the quick anion exchange and adsorption on the vacant site available onto the CuAl-LDH/SWCNTs nanocomposite. Thereafter, an adsorption-desorption equilibrium is established between the IC molecules in the solution and adsorbed on CuAl-LDH/ SWCNTs nanocomposite surface. ${ }^{36}$ To get more information about the adsorption-desorption equilibrium and rate of IC adsorption, the pseudo-first-order, ${ }^{45}$ and pseudo-second-order ${ }^{46}$ models were applied to the obtained data. The linear equation for the pseudo-first order, pseudo-second order are:

$$
\begin{gathered}
\log \left(q_{\mathrm{e}}-q_{t}\right)=\log q_{\mathrm{e}}-\frac{k_{1} t}{2.303} \\
\frac{t}{q_{t}}=\frac{1}{k_{2} q_{\mathrm{e}}^{2}}+\frac{t}{q_{\mathrm{e}}}
\end{gathered}
$$

where $q_{t}$ and $q_{\mathrm{e}}$ are the IC adsorption capacity $\left(\mathrm{mg} \mathrm{g}^{-1}\right)$ onto CuAl-LDH/SWCNTs nanocomposite at time $t(\mathrm{~min})$ and equilibrium, respectively. $k_{1}(1 / \mathrm{min})$ and $k_{2}\left(\mathrm{~g} \mathrm{mg}^{-1} \mathrm{~min}^{-1}\right)$ represent the rate constant for pseudo-first-order and the pseudosecond-order. Fig. $7 \mathrm{~b}$ and $\mathrm{c}$ show the respective plots for the applied kinetic models and the calculated values for each model are given in Table 3. The calculated values indicated that the adsorption of IC onto CuAl-LDH/SWCNTs nanocomposite followed the pseudo-second-order kinetic model because of higher
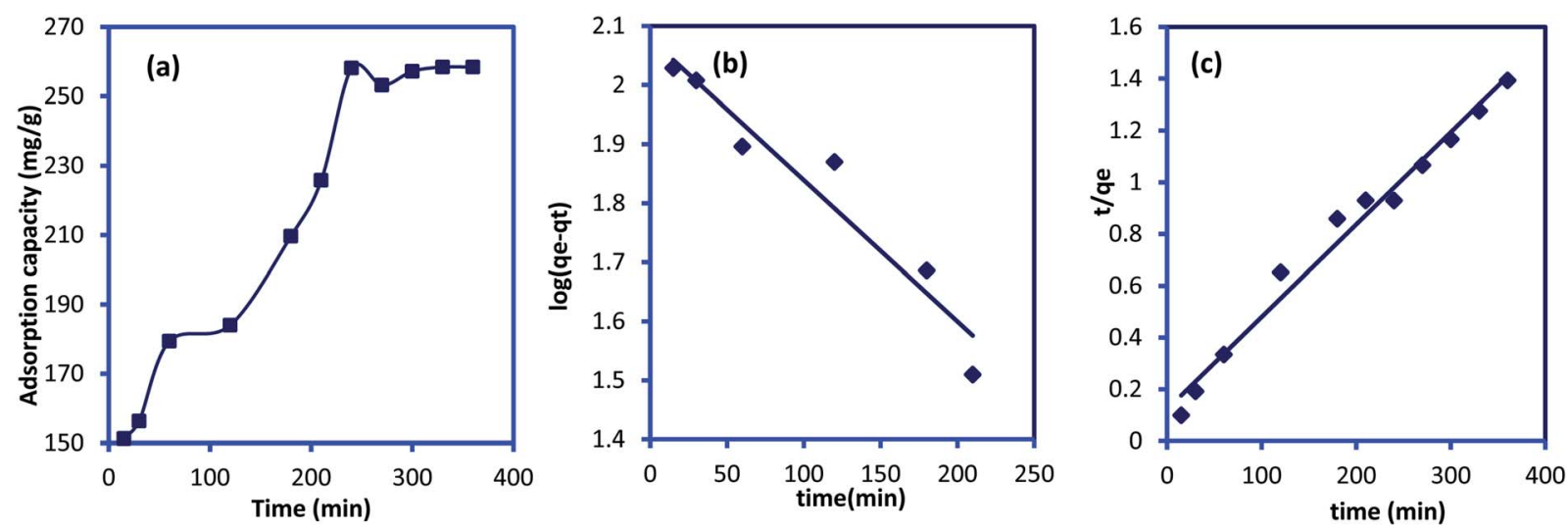

Fig. 7 (a) Effect of contact time on IC dye adsorption onto CuAl-LDH/SWCNTs nanocomposite $\left(\mathrm{m} 0.01 \mathrm{~g}, \mathrm{~V} 20 \mathrm{ml}\right.$, temp. $20^{\circ} \mathrm{C}$, conc. $300 \mathrm{mg} \mathrm{L}^{-1}$ ), and plot for (b) pseudo-first-order (c) pseudo-second order kinetic models. 
$12 \mathrm{~S}$. Sohrabnezhad and A. Pourahmad, Comparison absorption of new methylene blue dye in zeolite and nanocrystal zeolite, Desalination, 2010, 256, 84-89.

13 S. S. Tahir and N. Rauf, Removal of a cationic dye from aqueous solutions by adsorption onto bentonite clay, Chemosphere, 2006, 63, 1842-1848.

$14 \mathrm{G}$. Crini, Kinetic and equilibrium studies on the removal of cationic dyes from aqueous solution by adsorption onto a cyclodextrin polymer, Dyes Pigm., 2008, 77, 415-426.

15 I. Mohmood, C. B. Lopes, I. Lopes, I. Ahmad, A. C. Duarte and E. Pereira, Nanoscale materials and their use in water contaminants removal-a review, Environ. Sci. Pollut. Res., 2013, 20, 1239-1260.

16 I. Mobasherpour, E. Salahi and M. Ebrahimi, Thermodynamics and kinetics of adsorption of $\mathrm{Cu}(\mathrm{II})$ from aqueous solutions onto multi-walled carbon nanotubes, $J$. Saudi Chem. Soc., 2014, 18, 792-801.

17 F. M. Machado, C. P. Bergmann, E. C. Lima, B. Royer, F. E. de Souza, I. M. Jauris and S. B. Fagan, Adsorption of Reactive Blue 4 dye from water solutions by carbon nanotubes: experiment and theory, Phys. Chem. Chem. Phys., 2012, 14, 11139-11153.

18 C. Oueiny, S. Berlioz and F. X. Perrin, Carbon nanotubepolyaniline composites, Prog. Polym. Sci., 2014, 39, 707-748.

19 K. Osler, N. Twala, O. O. Oluwasina and M. O. Daramola, Synthesis and performance evaluation of chitosan/carbon nanotube (chitosan/MWCNT) composite adsorbent for post-combustion carbon dioxide capture, Energy Procedia, 2017, 114, 2330-2335.

20 J. G. Yu, X. H. Zhao, H. Yang, X. H. Chen, Q. Yang, L. Y. Yu and X. Q. Chen, Aqueous adsorption and removal of organic contaminants by carbon nanotubes, Sci. Total Environ., 2014, 482, 241-251.

21 S. Yang, L. Wang, X. Zhang, W. Yang and G. Song, Enhanced adsorption of Congo red dye by functionalized carbon nanotube/mixed metal oxides nanocomposites derived from layered double hydroxide precursor, Chem. Eng. J., 2015, 275, 315-321.

22 I. Ali, New Generation adsorbents for water treatment, Chem. Rev., 2012, 112, 5073-5091.

23 Q. Wang and D. O'Hare, Recent advances in the synthesis and application of layered double hydroxide (LDH) nanosheets, Chem. Rev., 2012, 112, 4124-4155.

24 L. Mohapatra and K. Parida, A review on the recent progress, challenges and perspective of layered double hydroxides as promising photocatalysts, J. Mater. Chem. A, 2016, 4, 10744-10766.

25 L. Ma, Q. Wang, S. M. Islam, Y. Liu, S. Ma and M. G. Kanatzidis, highly selective and efficient removal of heavy metals by layered double hydroxide intercalated with the $\mathrm{MoS}_{4}{ }^{2-}$ ion, J. Am. Chem. Soc., 2016, 138, 2858-2866.

26 M. Zubair, M. Daud, G. McKay, F. Shehzad and M. A. AlHarthi, Recent progress in layered double hydroxides (LDH)-containing hybrids as adsorbents for water remediation, Appl. Clay Sci., 2017, 143, 279-292.

27 N. S. Ahmed, R. Menzel, Y. Wang, A. G. Gallastegui, S. M. Bawaked, A. Y. Obaid, S. N. Basahel and M. Mokhtar,
Graphene-oxide-supported $\mathrm{CuAl}$ and CoAl layered double hydroxides as enhanced catalysts for carbon-carbon coupling via Ullmann reaction, J. Solid State Chem., 2017, 246, 130-137.

28 Z. Muda, N. Hashim, I. M. Isa, S. A. Bakar and S. M. Sidik, Synthesis and characterization of mesoporous zinc layered hydroxide-isoprocarb nanocomposite, J. Saudi Chem. Soc., 2018, DOI: 10.1016/j.jscs.2018.08.012.

29 S. Wan, S. Wang, Y. Li and B. Gao, Functionalizing biochar with $\mathrm{Mg}$-Al and $\mathrm{Mg}-\mathrm{Fe}$ layered double hydroxides for removal of phosphate from aqueous solutions, J. Ind. Eng. Chem., 2017, 47, 246-253.

30 M. N. Sepehr, T. J. Al-Musawi, E. Ghahramani, H. Kazemian and M. Zarrabi, Adsorption performance of magnesium/ aluminum layered double hydroxide nanoparticles for metronidazole from aqueous solution, Arabian J. Chem., 2017, 10, 611-623.

31 S. Das, S. K. Dash and K. M. Parida, Kinetics, Isotherm, and Thermodynamic Study for Ultrafast Adsorption of Azo Dye by an Efficient Sorbent: Ternary $\mathrm{Mg} /(\mathrm{Al}+\mathrm{Fe})$ Layered Double Hydroxides, ACS Omega, 2018, 3, 2532-2545.

32 A. Malak-Polaczyk, C. Vix-Guterl and E. Frackowiak, Carbon/ layered double hydroxide (LDH) composites for supercapacitor application, Energy Fuels, 2010, 24, 33463351.

33 B. Chai, T. Peng, X. Zhang, J. Mao, K. Li and X. Zhang, Synthesis of C 60-decorated SWCNTs (C 60-d-CNTs) and its $\mathrm{TiO}_{2}$-based nanocomposite with enhanced photocatalytic activity for hydrogen production, Dalton Trans., 2013, 42, 3402-3409.

34 Y. Li, X. J. Huang, S. H. Heo, C. C. Li, Y. K. Choi, W. P. Cai and S. O. Cho, Superhydrophobic bionic surfaces with hierarchical microsphere/SWCNT composite arrays, Langmuir, 2007, 23, 2169-2174.

35 H. Li, Q. Deng, J. Liu, W. Hou, N. Du, R. Zhang and X. Tao, Synthesis, characterization and enhanced visible light photocatalytic activity of $\mathrm{Bi}_{2} \mathrm{MoO}_{6} / \mathrm{Zn}$-Al layered double hydroxide hierarchical heterostructures, Catal. Sci. Technol., 2014, 4, 1028-1037.

36 S. Wan, S. Wang, Y. Li and B. Gao, Functionalizing biochar with $\mathrm{Mg}$-Al and $\mathrm{Mg}-\mathrm{Fe}$ layered double hydroxides for removal of phosphate from aqueous solutions, J. Ind. Eng. Chem., 2017, 47, 246-253.

37 A. Mittal, J. Mittal and L. Kurup, Utilization of hen feathers for the adsorption of indigo carmine from simulated effluents, J. Environ. Prot. Sci., 2007, 1, 92-100.

$38 \mathrm{I}$. Langmuir, The constitution and fundamentals properties of solids and liquids, J. Am. Chem. Soc., 1916, 38, 2221-2295.

39 H. M. F. Freundlich, Over the adsorption in solution, J. Phys. Chem., 1906, 57, 1100-1107.

40 S. M. de Oliveira Brito, H. M. C. Andrade, L. F. Soares and R. P. de Azevedo, Brazil nut shells as a new biosorbent to remove methylene blue and indigo carmine from aqueous solutions, J. Hazard. Mater., 2010, 174, 84-92.

41 P. B. Wagh and V. S. Shrivastava, Removal of indigo carmine dye by using palm wood cellulose activated carbon in aqueous solution: a kinetic and equilibrium study, 
International Journal of Latest Technology in Engineering, Management \& Applied Science, 2015, IV, 106-114.

42 Y. Hu, X. Chen, Z. Liu, G. Wang and S. Liao, Activated carbon doped with biogenic manganese oxides for the removal of indigo carmine, J. Environ. Manage., 2016, 166, 512-518.

43 R. Kumar, M. A. Barakat and F. A. Alseroury, Oxidized gC3N4/polyaniline nanofiber composite for the selective removal of hexavalent chromium, Sci. Rep., 2017, 7, 12850.

44 S. Hashemian, B. Sadeghi and M. Mangeli, Hydrothermal synthesis of nano cavities of Al-MCF for adsorption of indigo carmine from aqueous solution, J. Ind. Eng. Chem., 2015, 21, 423-427.

45 S. Lagergren, About the theory of so-called adsorption of soluble substances, K. Vetensk. Acad. Handl., 1898, 24, 1-39.

46 Y. S. Ho, J. C. Y. Ng and G. McKay, Kinetics of pollutant sorption by biosorbents: review, Sep. Purif. Methods, 2000, 29, 189-232.

47 M. A. Barakat, A. M. Al-Ansari and R. Kumar, Synthesis and characterization of Fe-Al binary oxyhydroxides/MWCNTs nanocomposite for the removal of $\mathrm{Cr}(\mathrm{vI})$ from aqueous solution, J. Taiwan Inst. Chem. Eng., 2016, 63, 303-311. 